\title{
Interhemispheric transcallosal route for resection of anterior third ventricular lesions
}

\author{
Aaron A. Cohen-Gadol, M.D., M.Sc. \\ Goodman Campbell Brain and Spine, Indiana University Department of Neurological Surgery, Indianapolis, \\ Indiana
}

Anterior third ventricular lesions present with a variety of symptoms related to cerebrospinal fluid flow obstruction and mass effect. Colloid cysts are among the most common lesions in the region. They usually present with ventriculomegaly, leading to headaches, vertigo, or, rarely, decreased mental status due to the development of acute hydrocephalus. Many patients become aware of their asymptomatic colloid cysts during imaging evaluation related to other conditions. Symptomatic cysts require removal, and larger asymptomatic colloid cysts $(>1 \mathrm{~cm})$ in younger patients may also need to be excised despite a lack of symptoms.

A variety of surgical routes have been described to access and remove colloid cysts. Endoscopic approaches are least invasive and provide adequate decompression and removal of the cyst wall. However, presence of ventriculomagaly may be necessary to provide adequate working space for endoscopic resection. Transcallosal interhemispheric and transcortical routes are typically reserved for patients with symptomatic or large asymptomatic cysts without any significant hydrocephalus. Transcortical route may carry a slightly increased risk of seizures due to cortical disruption. Interhemispheric transcallosal approach with the use of microsurgical techniques minimizes injury to normal structures. In this video, the author describes his technique for transcallosal resection of a large colloid cyst in the absence of significant ventriculomegaly. Methods to minimize complications are reviewed.

The video can be found here: http://youtu.be/KzC8QYsTKeg.

(http://thejns.org/doi/abs/10.3171/2013.V1.FOCUS12340)

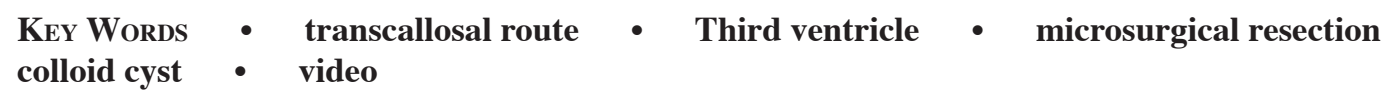

\footnotetext{
Manuscript submitted October 15, 2012.

Accepted November 15, 2012.

Please include this information when citing this paper: DOI: 10.3171/2013.V1.FOCUS12340.

Address correspondence to: Aaron A. Cohen-Gadol, M.D., M.Sc., Goodman Campbell Brain and Spine, Indiana University Department of Neurological Surgery, 1801 North Senate Boulevard \#610, Indianapolis, Indiana 46202. email: acohenmd@ gmail.com.
} 